\title{
CƠ SỞ CỦA VIỆC ĐỀ XUẤT DANH MỤC PHƯƠNG TIỆN ĐO ĐẠC BẢN ĐỒ CẦN KIỂM ĐỊNH Ở VIẸTT NAM
}

\author{
BÙI ĐĂNG QUANG ${ }^{(1)}$, VŨ TIẾN QUANG ${ }^{(2)}$ \\ ${ }^{(1)}$ Cuc Đo đạc, Bản đồ và Thông tin địa lý Việt Nam \\ ${ }^{(2)}$ Hội Trắc địa - Bản đồ và Viễn thám Việt Nam
}

\section{Tóm tắt:}

Trong bài viết này đề cập đến việc kiểm định phưong tiện đo đạc bản đồ ở Việt Nam - một vấn đề cần thiết nhung chua được thực hiện đầy đủ tù nhiều năm nay, đồng thời đura ra đề xuất về danh muc phưong tiện đo đạc bản đồ cần phải kiểm định trong thời gian tới nhằm tăng cuờng quản lý nhà nước về công tác kiểm định phương tiện đo theo hướng đã được quy định trong Luật Đo lường số: 04/2011/QH13 và Luật Đo đạc và bản đồ số: 27/2018/QH14.

\section{1. Đặt vấn đề}

Đo đạc bản đồ là lĩnh vực kỹ thuật đặc biệt mà sản phẩm của nó chủ yếu là các thông tin, dữ liệu định lượng có độ chính xác cao như tọa độ, độ cao, bản đồ, cơ sở dữ liệu .v.v. Để đảm bảo cho tính chính xác, tính thống nhất của sản phẩm đo đạc bản đồ, trước hết các sản phẩm này phải được sản xuất bằng những phương tiện đo đạc chuẩn. Để có được phương tiện đo đạc bản đồ hoạt động đạt được độ chính xác theo tiêu chuẩn trước hết cần phải đảm bảo rằng phương tiện đó được làm ra từ một nhà sản xuất thiết bị tiêu chuẩn và đang trong thời hạn kiểm định.

Rõ ràng là việc kiểm định phương tiện đo đạc bản đồ là một hoạt động mang tính nguyên tắc không thể thiếu ở mọi quốc gia để đảm bảo độ chính xác hoạt động của phương tiện đo. Với vai trò đó, trong lĩnh vực đo đạc bản đồ, các quốc gia đều hướng tới việc xây dựng cho mình một hệ thống trong đó bao gồm các cơ quan quản lý, các văn bản pháp lý, hạ tầng kỹ thuật để đảm bảo cho việc quản lý, thực thi việc kiểm định phương tiện đo đạc, đảm bảo tính thống nhất sản phẩm đo đạc bản đồ quốc gia cũng như trao đổi thông tin đo đạc bản đồ quốc tế.

Ở Việt Nam, hiện nay trong các văn bản pháp luật về đo đạc bản đồ đều đề cập đến việc phương tiện, thiết bị sử dụng trong các công trình đo đạc bản đồ cần được kiểm định, kiểm nghiệm, tuy nhiên các quy định thường không rõ ràng, đầy đủ và thống nhất, thường chỉ đề cập đến quá trình kiểm nghiệm, các quy định chủ yếu cho các loại máy lạc hậu mà hiện nay hầu như không sử dụng. Về hạ tầng kỹ thuật, ngoài các cơ sở kiểm định phương tiện đo trong phòng, trước đây Cục Đo đạc và Bản đồ Nhà nước đã tổ chức xây dựng và đưa vào sử dụng các bãi chuẩn kiểm định ngoài trời từ năm 1985 tại Xuân Mai - Hà Nội và Thủ Đức - Thành phố Hồ Chí Minh. Do sự phát triển kinh tế xã hội, các bãi chuẩn này không còn tồn tại từ nhiều năm nay. Từ các lý do nêu trên, đến nay công tác kiểm định phương tiện đo đạc như máy toàn đạc điện tử, máy thu tín hiệu vệ tinh GNSS chủ yếu còn mang tính hình thức.

\section{Kiểm định phương tiện đo đạc bản đồ trên thế giới và ở Việt Nam}

Hiện nay công nghệ đo đạc bản đồ trên thế giới và Việt Nam ngày một phát triển mạnh mẽ. Các phương tiện, thiết bị đo đạc cơ bản (đo góc, đo cạn, đo cao, đo trọng lưc) truyền thống trước đây đã trở nên lạc hậu, đã được thay thế bằng các phương tiện, thiết bị công nghệ số ngày càng có độ chính xác cao và hoàn thiện hơn từ các hãng nổi tiếng như Trimble, Ashtech, Sokkia, Leica, .v.v. Tuy nhiên, cũng cần phải thấy rằng, phương tiện, thiết bị đo đạc bản đồ dạng số, hiện đại cũng không thể bỏ qua được công tác kiểm định, kiểm nghiệm, hiệu chỉnh các 
chỉ tiêu cơ bản, truyền thống của phương tiện đo. Vẫn còn đó sai số $2 \mathrm{C}, \mathrm{MO}$ ở máy đo góc điện tử, sai số góc “i”, sai số mã vạch mia thủy chuẩn điện tử, các chức năng, độ chính xác đo dài trong máy toàn đạc điện tử không phải là bất biến nếu không được kiểm định, công nghệ đo GNSS không phải là tuyệt đối chính xác mà còn phụ thuộc vào loại phương tiện, thiết bị, vào tuổi đời, hiện trạng máy thu tín hiệu vệ tinh. Nói tóm lại nhiệm vụ kiểm định phương tiện đo đạc bản đồ vẫn còn nguyên vai trò truyền thống của nó dù đến nay thế giới đang ở giai đoạn công nghệ 4.0.

Điều này thể hiện ở chỗ nhiều quốc gia phát triển trên thế giới như Mỹ, Nga, các quốc gia Châu Âu, Canada, Nhật Bản, Hàn Quốc, Trung Quốc đã xây dựng hệ thống tiêu chuẩn kỹ thuật, cơ sở kiểm định phương tiện đo đạc bản đồ hoàn chỉnh, đảm bảo tính chính xác, tính đồng bộ, tính đồng nhất về chất lượng phương tiện đo đạc bản đồ cho mỗi quốc gia và trong trao đổi quốc tế. Hiệp hội tiêu chuẩn quốc tế (International Organization for Standardization - ISO) với loạt các tiêu chuẩn ISO 17123 đã xây dựng các tiêu chuẩn về quy trình để kiểm tra phương tiện, thiết bị khảo sát, đo đạc bản đồ, theo đó tùy theo điều kiện, trình độ về kỹ thuật, phương pháp quản lý mỗi quốc gia có thể áp dụng các tiêu chuẩn ISO 17123 hoặc xây dựng những quy định riêng về công tác kiểm định phương tiện, thiết bị đo đạc bản đồ đảm bảo chất lượng ổn định trong suốt quá trình sản xuất.

Ở Việt Nam, quy định trong quy phạm đo đạc bản đồ tại các thời điểm 1976, 1990, 1999 đều có điều khoản quy định về kiểm định, kiểm nghiệm phương tiện, thiết bị đo đạc bản đồ. Luật Đo đạc và bản đồ số $27 / 2018 / \mathrm{QH} 14$ ngày 14 tháng 6 năm 2018 cũng ghi nhận, khẳng định: "Phương tiện đo được sử dụng trong hoạt động đo đạc và bản đồ phải được kiểm định, hiệu chuẩn; Bộ Tài nguyên và Môi truờng đề xuất danh muc phuơng tiện đo phải kiểm định trong hoạt động đo đạc và bản đồ". Vấn đề kiểm định phương tiện đo đạc bản đồ cũng đã được đề cập và quy định trong Luật Đo lường số: 04/2011/QH13 có hiệu lực 01 tháng 7 năm 2012 và các thông tư hướng dẫn thi hành số: 23/2013/TT-BKHCN ngày 26 tháng 9 năm 2013 và Thông tư số: 07/2019/TT-BKHCN ngày 26 tháng 7 năm 2019 của Bộ Khoa học và Công nghệ, trong đó quy định trách nhiệm của tổ chức, cá nhân sử dụng phương tiện đo là "Bảo đảm các điều kiện bảo quản, sử dụng phuoong tiện đo theo quy định của nhà sản xuất, yêu cầu kỹ thuật đo lường của co quan nhà nước về đo lường có thẩm quyền; duy trì đặc tính kỹ thuật đo luòng của phưong tiện đo trong suốt quá trình sử dụng và giữa hai kỳ kiểm định".

Thực tế công tác kiểm định phương tiện đo đạc bản đồ của Việt Nam đã không được triển khai đúng vai trò từ nhiều năm nay do những nguyên nhân khách quan và chủ quan.

Nguyên nhân khách quan có thể chỉ ra đó là các bãi chuẩn kiểm định phương tiện đo đạc bản đồ của ngành đo đạc bản đồ được xây dựng đã lâu, bị hư hại do sự phát triển kinh tế, xã hội nhưng không được khôi phục, từ đó tổ chức, cá nhân sử dụng phương tiện đo đạc bản đồ (chủ yếu là máy toàn đạc điện tử, máy thu tín hiệu vệ tinh GNSS) không có nơi để thực hiện công tác kiểm định. Cục Đo đạc, Bản đồ và Thông tin địa lý Việt Nam cũng đã có đề xuất dự án khôi phục, xây dựng mới cơ sở kiểm định phương tiện đo đạc bản đồ nhưng vì nhiều lý do, khó khăn khác nhau nên chưa được triển khai từ nhiều năm qua. Hiện tại Cục đang triển khai đề tài khoa học cấp Bộ "Nghiên cúu co" sở khoa hoc xây dựng quy định về công tác kiểm định, hiệu chuẩn phuơng tiện đo trong lĩnh vưc đo đạc bản đồ" với mục đích hoàn thiện hệ thống kiểm định phương tiện đo đạc bản đồ ở Việt Nam hiện nay.

Nguyên nhân chủ quan có thể nói đó là sự không đồng bộ về quản lý nhà nước về kiểm định phương tiện đo đạc bản đồ, thể hiện ở chỗ quy định bắt buộc về kiểm định thì đã có nhưng chưa có hướng dẫn cụ thể về nội dung, phương pháp, cách thức kiểm định; Trong khi đó, các cơ sở hoạt động về kiểm định phương tiện đo đạc chưa đầu tư nhiều về nghiên cứu xây dựng các quy trình nội bộ một cách bài bản dẫn tới chất lượng công tác kiểm định chưa đáp ứng được yêu cầu theo Luật định. 
Dù thực tế vấn đề kiểm định phương tiện đo đạc bản đồ ở Việt Nam còn có những khó khăn, tồn tại như nêu trên nhưng trong thời gian tới công tác kiểm định phương tiện đo đạc bản đồ sẽ phải thực hiện đúng, đồng bộ theo các văn bản luật pháp đã có trong Luật Đo lường sô: 04/2011/QH13, Luật Đo đạc và bản đồ số: 27/2018/QH14 cũng như các văn bản dưới luật để công tác kiểm định phương tiện đo đạc bản đồ đi đúng theo hướng tuân thủ pháp luật.

\section{Các quy định pháp luật cơ bản về kiểm định phương tiện đo đạc ở Việt Nam}

Luật Đo lường số: 04/2011/QH13 và các Thông tư số: 23/2013/TT-BKHCN, 07/2019/TTBKHCN của Bộ Khoa học và Công nghệ đã quy định rõ về kiểm định phương tiện đo lường nói chung, với những nội dung quan trọng liên quan đến đo đạc bản đồ như sau:

- Phương tiện đo nhóm 2 phải được kiểm định ban đầu trước khi đưa vào sử dụng, kiểm định định kỳ trong quá trình sử dụng, kiểm định sau sửa chữa. Phương tiện đo nhóm 2 phải được kiểm soát về đo lường bằng một hoặc một số biện pháp: phê duyệt mẫu khi sản xuất, nhập khẩu; kiểm định ban đầu trước khi đưa vào sử dụng; kiểm định định kỳ trong quá trình sử dụng; kiểm định sau sửa chữa;

- Việc kiểm định phương tiện đo do tổ chức kiểm định thực hiện để đánh giá, xác nhận đặc tính kỹ thuật đo lường của phương tiện đo theo yêu cầu kỹ thuật đo lường;

- Tổ chức kiểm định là tổ chức đáp ứng các điều kiện theo quy định của Luật này và quy định của pháp luật có liên quan, được cơ quan nhà nước về đo lường có thẩm quyền xem xét, đưa vào danh sách để tổ chức, cá nhân lựa chọn sử dụng dịch vụ kiểm định, hiệu chuẩn, thử nghiệm phương tiện đo, chuẩn đo lường.

Các quy định này của Luật Đo lường mang tính bao trùm cho tất cả các phương tiện đo ở Việt Nam trong đó có các phương tiện đo đạc bản đồ. Luật Đo đạc và bản đồ số: 27/2018/QH14 ngày 14 tháng 6 năm 2018 quy định: "Phuoong tiện đo được sủ dụng trong hoạt động đo đạc và bản đồ phải được kiểm định, hiệu chuẩn; Bộ Tài nguyên và Môi trường đề xuất danh muc phuoong tiện đo phải kiểm định trong hoạt động đo đạc và bản đồ". Từ các quy định này có thể thấy được các nội dung mang tính quy định pháp luật đối với phương tiện đo đạc bản đồ, đó là:

- Phương tiện đo đạc bản đồ phải được kiểm định ban đầu (xuất xưởng, nhập khẩu) trước khi đưa vào sử dụng, kiểm định định kỳ trong quá trình sử dụng, kiểm định sau sửa chữa;

- Tổ chức kiểm định là tổ chức theo quy định ở Luật này là cơ quan, đơn vị được cơ quan nhà nước về đo lường có thẩm quyền xem xét, đưa vào danh sách để tổ chức, cá nhân lựa chọn sử dụng dịch vụ kiểm định, hiệu chuẩn, thử nghiệm phương tiện đo, chuẩn đo lường. Điều này cho thấy khái niệm "Tổ chức kiểm định" khá rộng, không chỉ cơ quan quản lý nhà nước về đo đạc bản đồ mà còn là tổ chức khác đáp ứng yêu cầu của cơ quan nhà nước về đo lường có thẩm quyền;

- Danh mục phương tiện đo đạc bản đồ phải được kiểm định thuộc danh mục phương tiện đo nhóm 2, được cơ quan quản lý nhà nước về đo lường là $\mathrm{Bộ} \mathrm{Khoa} \mathrm{học} \mathrm{và} \mathrm{Công} \mathrm{nghệ} \mathrm{ban} \mathrm{hành}$ dưới dạng thông tư trên cơ sở đề xuất của Bộ Tài nguyên và Môi trường (mà cụ thể là ngành đo đạc bản đồ).

Như vậy có thể thấy rằng vai trò của Cục Đo đạc, Bản đồ và Thông tin địa lý Việt Nam trong việc kiểm định phương tiện đo đạc bản đồ rất quan trọng, vừa là cơ quan chủ động đề xuất danh mục phương tiện, chu kỳ cần kiểm định, đồng thời là cơ quan tham gia vào việc triển khai tổ chức việc kiểm định phương tiện đo đạc bản đồ để đảm bảo đưa việc kiểm định phương tiện đo đạc tuân thủ đúng pháp luật.

\section{4. Đề xuất hoàn thiện danh mục phương tiện đo đạc bản đồ cần kiểm định}

Ở Việt Nam thời kỳ trước năm 1985 là thời kỳ Việt Nam có đủ hạ tầng kỹ thuật cho việc 
kiểm định phương tiện đo đạc bản đồ thì có thể thấy khi đó số lượng cũng như chủng loại phương tiện, thiết bị đo dài, đo cao cần kiểm định rất ít, chỉ có một số phương tiện, thiết bị đo dài như thước thép, máy đo dài điện quang CT5, DI3S..., máy thủy chuẩn với mia inva như Ni004, Ni007, WILD. Đến nay, khi mà công nghệ chế tạo cơ khí, công nghệ điện tử, công nghệ số đã đạt độ chính xác cao thì thiết bị đo dài được tích hợp trong máy toàn đạc điện tử đã trở nên phổ biến rộng rãi; phương tiện đo độ cao ngoài các máy truyền thống đã có thêm phương tiện đo độ cao hình học dạng số; một loạt phương tiện, thiết bị công nghệ đo đạc mới như máy đo GNSS, máy quét lidar, máy chụp ảnh số, máy đo sâu hồi âm, máy đo sâu công trình ngầm đã đặt ra cho công tác kiểm định phương tiện đo phục vụ quản lý nhà nước về đo đạc bản đồ đang ngày càng trở nên cấp thiết. Để đáp ứng yêu cầu quản lý đúng pháp luật về công tác kiểm định phương tiện đo thì ngành đo đạc bản đồ ngoài việc xây dựng mới hệ thống văn bản kỹ thuật, xây dựng hạ tầng kỹ thuật thực hiện công tác kiểm định còn phải kết hợp chặt chẽ với Tổng cục Tiêu chuẩn Đo lường Chất lượng - Bộ Khoa học và Công nghệ để thường xuyên điều chỉnh, đề xuất ban hành danh mục phương tiện đo đạc bản đồ cần kiểm định (thuộc phương tiện đo nhóm 2) cũng như phối hợp biên soạn các quy trình kiểm định của từng loại phương tiện đo đạc bản đồ một cách đồng bộ, làm cơ sở cho công tác kiểm định phương tiện đo đạc bản đồ hoạt động theo đúng vai trò pháp luật.

Trên cơ sở yêu cầu thực tế về công tác quản lý chất lượng sản phẩm đo đạc và bản đồ, Cục Đo đạc, Bản đồ và Thông tin địa lý Việt Nam đã xây dựng, dự thảo danh mục phương tiện đo cần kiểm định và đã được chấp thuận đưa vào danh mục phương tiện đo nhóm 2 trong Thông tư số 07/2019/TT-BKHCN ban hành 26 tháng 7 năm 2019 của Bộ Khoa học và Công nghệ.

Tuy nhiên, trong thời gian tới, để đảm bảo tính đồng bộ của việc kiểm định phương tiện đo đạc bản đồ trong điều kiện phương tiện, thiết bị công nghệ đo đạc đang ngày càng phát triển như hiện nay thì cần thiết phải đề xuất bổ sung danh mục mới mang tính tổng quát hơn, đầy đủ hơn về các loại phương tiện đo cần kiểm định, chu kỳ kiểm định như sau:

\begin{tabular}{|c|c|c|c|c|c|}
\hline \multirow[b]{2}{*}{ TT } & \multirow[b]{2}{*}{ Tên phương tiện đo } & \multicolumn{3}{|c|}{ Kiểm định } & \multirow{2}{*}{$\begin{array}{c}\text { Chu kỳ } \\
\text { kiểm định }\end{array}$} \\
\hline & & $\begin{array}{l}\text { Ban } \\
\text { đầu }\end{array}$ & $\begin{array}{c}\text { Định } \\
\text { kỳ }\end{array}$ & $\begin{array}{c}\text { Sau sửa } \\
\text { chữa }\end{array}$ & \\
\hline 1 & Phương tiện đo khoàng cách quang điện & $\mathrm{x}$ & $\mathrm{x}$ & $\mathrm{x}$ & 12 tháng \\
\hline 2 & Phương tiện đo độ sâu đáy nước & $\mathrm{x}$ & $\mathrm{x}$ & $\mathrm{x}$ & 12 tháng \\
\hline 3 & Phương tiện đo thủy chuẩn & $\mathrm{x}$ & $\mathrm{x}$ & $\mathrm{x}$ & 12 tháng \\
\hline 4 & Toàn đạc điện tử & $\mathrm{x}$ & $\mathrm{x}$ & $\mathrm{x}$ & 12 tháng \\
\hline 5 & Phương tiện đo kinh vĩ & $\mathrm{x}$ & $\mathrm{x}$ & $\mathrm{x}$ & 12 tháng \\
\hline 6 & Phương tiện đo định vị bằng vệ tỉnh & $\mathrm{x}$ & $\mathrm{x}$ & $\mathrm{x}$ & 12 tháng \\
\hline 7 & Phương tiện đo độ sâu công trình ngầm & $\mathrm{x}$ & $\mathrm{x}$ & $\mathrm{x}$ & 24 tháng \\
\hline 8 & Máy chụp ảnh & $\mathrm{x}$ & $\mathrm{x}$ & $\mathrm{x}$ & 24 tháng \\
\hline 9 & Phương tiện quét lidar & $\mathrm{x}$ & $\mathrm{x}$ & $\mathrm{x}$ & 24 tháng \\
\hline 10 & Phương tiên đo trong lực & $\mathrm{x}$ & $\mathrm{x}$ & $\mathrm{x}$ & 24 tháng \\
\hline
\end{tabular}

\section{Kết luận:}

Công nghệ đo đạc bản đồ ngày càng phát triển mạnh mẽ đi kèm với nhiều phương tiện, thiết bị mới do vậy trong thời gian tới cần ban hành bổ sung danh mục phương tiện đo đạc bản đồ phải kiểm định bắt buộc, đồng thời cần có những nghiên cứu về quy trình kiểm định cho các loại phương tiện đo mới này.

Với tác động của Luật Đo đạc và bản đồ, Luật Đo lường và các văn bản dưới Luật cùng với sự quan tâm của các cơ quan quản lý nhà nước về đo đạc bản đồ, công tác kiểm định phương tiện đo đạc bản đồ sẽ được nâng tầm đúng với vai trò, vị trí vốn có, góp phần đảm bảo tiêu chuẩn chất lượng các sản phẩm đo đạc bản đồ - một nền tảng cơ bản để xây dựng, đưa nền kinh tế số của Việt Nam phát triển, hội nhập với các quốc gia trong khu vực và thế giới. $O$

\section{Tài liệu tham khảo}

[1]. ISO 71723 Optics and optical instruments, Field procedures for testing geodetic and surveying instruments.

[2]. Luật Đo lường số 04/2011/QH13.

[3]. Luật Đo đạc và bản đồ số 27/2018/QH14. 
[4]. Thông tư số 23/2013/TT-BKHCN ngày 26 tháng 9 năm 2013 quy định về đo lường đối với phương tiện nhóm 2 .

[5]. Thông tư số 07/2019/TT-BKHCN ngày
26 tháng 7 năm 2019 Sửa đổi, bổ sung một số điều của Thông tư số 23/2013/TT-BKHCN ngày 26 tháng 9 năm 2013 của Bộ trưởng Bộ Khoa học Công nghệ quy định về đo lường đối với phương tiện nhóm 2.0

\section{Summary}

A basis of proposal for survey and mapping instrument list needs to be verified in Vietnam

Bui Dang Quang, Department of Survey, Mapping and Geographic information Vietnam

Vu Tien Quang, Vietnam Association of Geodesy Cartography and Remote Sensing

This article discusses on the verification of surveying and mapping equipment in Vietnam - a necessary issue but has not been fully implemented for many years, and also makes recommendations on verification of surveying and mapping equipment that need to be tested in the near future to strengthen the state management of the measuring device verification in the direction specified in the Law of Measurement No. 04/2011/QH13 and the Law on Survey and Mapping No. 27/2018/QH14.O

\section{XÁC ĐỊNH MẶT BIỂN TRUNG BÌNH}

\section{(Tiếp theo trang 17)}

[6]. Turner, J.H., Iliffe, J.C., Ziebart, M.K. and Jones, C., 2013. Global Ocean tide Models: Assessment and Use within a Surface Model of Lowest Astronomical Tide. In: Marine Geodesy, 36 : 123 - 137, 2013. Taylor \& Francis Group, LLC. ISSN: 0149-0419 print/1521-060X online, DOI: 10.1080/01490419.2013.771717. Thư viện Viện Khoa học Đo đạc và Bản đồ. $\bigcirc$

\section{Summary}

\section{Determination of mean sea surface used for boundary between land and sea and serving the sea cadastral works}

\section{Ha Minh Hoa}

\section{Vietnam Institute of Geodesy and Cartography}

This article represents importance role of the mean low water surface in management of coastland scape. At present the mean low water surface was not determinined and there is not base for development of sea cadastral works. Detemination of the mean low water surface will increase the sea cadastral works in MONRE. $O$ 